OPEN ACCESS

Edited by:

Paolo Marzullo,

Università degli Studi del Piemonte

Orientale, Italy

Reviewed by:

Sean L. McGee,

Deakin University, Australia

Gianluca Aimaretti

University of Eastern Piedmont, Italy

*Correspondence:

Giovanni Ceccarini

giovanni.ceccarini@unipi.it

Specialty section

This article was submitted to

Obesity,

a section of the journa

Frontiers in Endocrinology

Received: 21 October 2019

Accepted: 21 January 2020

Published: 14 February 2020

Citation:

Ceccarini G, Magno S, Pelosini C,

Ferrari F, Sessa MR, Scabia G

Maffei M, Jéru I, Lascols O, Vigouroux C and Santini F (2020) Congenital Generalized Lipoatrophy (Berardinelli-Seip Syndrome) Type 1:

Description of Novel AGPAT2

Homozygous Variants Showing the Highly Heterogeneous Presentation of the Disease. Front. Endocrinol. 11:39.

doi: 10.3389/fendo.2020.00039

\section{Congenital Generalized Lipoatrophy (Berardinelli-Seip Syndrome) Type 1: Description of Novel AGPAT2 Homozygous Variants Showing the Highly Heterogeneous Presentation of the Disease}

Giovanni Ceccarini ${ }^{1 *}$, Silvia Magno ${ }^{1}$, Caterina Pelosini ${ }^{1,2}$, Federica Ferrari $^{1}$, Maria Rita Sessa ${ }^{2}$, Gaia Scabia ${ }^{1,3}$, Margherita Maffei ${ }^{1,3}$, Isabelle Jéru ${ }^{4,5}$, Olivier Lascols ${ }^{4,5}$, Corinne Vigouroux ${ }^{4,5,6}$ and Ferruccio Santini ${ }^{1}$

${ }^{1}$ Obesity and Lipodystrophy Center at Endocrinology Unit, University Hospital of Pisa, Pisa, Italy, ${ }^{2}$ Chemistry and Endocrinology Laboratory at University Hospital of Pisa, Pisa, Italy, ${ }^{3}$ Institute of Clinical Physiology, National Research Council, Pisa, Italy, ${ }^{4}$ Sorbonne Université, Inserm UMR_S 938, Centre de Recherche Saint-Antoine, Institut Hospitalo-Universitaire de Cardio-métabolisme et Nutrition (ICAN), Paris, France, ${ }^{5}$ Assistance Publique-Hôpitaux de Paris, Hôpital Saint-Antoine, Laboratoire Commun de Biologie et Génétique Moléculaires, Paris, France, ${ }^{6}$ Assistance Publique-Hôpitaux de Paris, Hôpital Saint-Antoine, Centre National de Référence des Pathologies Rares de l'Insulino-Sécrétion et de l'Insulino-Sensibilité (PRISIS), Service d'Endocrinologie, Diabétologie et Endocrinologie de la Reproduction, Paris, France

Berardinelli-Seip congenital lipoatrophy (BSCL) is characterized by near total fat atrophy, associated with the progressive development of metabolic complications. BSCL type 1 (BSCL1) is caused by mutations in AGPAT2, encoding 1-acylglycerol-3phosphate-O-acyltransferase $\beta$ (recently renamed lysophosphatidic acid acyltransferase beta), which catalyzes the transformation of lysophosphatidic acid in phosphatidic acid, the precursor of glycerophospholipids and triglycerides. BSCL1 is an autosomal recessive disease due to AGPAT2 pathogenic variants leading to a depletion of triglycerides inside the adipose organ, and to a defective signaling of key elements involved in proper adipogenesis. We herein investigated the characteristics of two AGPAT2 variants in Caucasian Italian patients with Berardinelli-Seip congenital lipoatrophy. The first patient exhibited a novel homozygous nonsense c.430 C > T AGPAT2 mutation (p.Gln144*) predicting the synthesis of a truncated enzyme of approximately half of the proper size. The second patient harbored a homozygous AGPAT2 missense variant (p.Arg159Cys), never described previously in BSCL1 patients: the segregation of the disease with the mutation in the pedigree of the family and the in silico analysis are compatible with a causative role of the p.Arg159Cys variant. We remark that BSCL1 can be clinically very heterogeneous at presentation and that the associated complications, occurring in the natural history of the disease, reduce life-expectancy. We point to the necessity for medical treatments capable of reducing the risk of cardiovascular death. In BSCL1 patients, the assessment of cardiovascular disease with conventional diagnostic means maybe particularly challenging.

Keywords: lipodystrophy, Berardinelli-Seip syndrome, BSCL1, AGPAT2, leptin 


\section{INTRODUCTION}

Congenital generalized lipodystrophy was first described by Waldemar Berardinelli in 1954 (1) and later on further outlined by Martin Seip (2).

Berardinelli-Seip congenital lipoatrophy (BSCL) is characterized by near total fat atrophy since birth, associated with the progressive development of metabolic complications (3). The most common are type 2 diabetes, severe hypertriglyceridemia, acute pancreatitis, hepatic steatosis, and hepatomegaly which are usually detected during infancy and adolescence; other features include, but are not restricted to, muscle pseudo-hypertrophy and acromegaloid appearance, umbilical hernia, polycystic ovary syndrome, cysts in the appendicular bones, cardiopathies, and cardiac rhythm disorders $(4,5)$. Depending on the underlying molecular cause, mechanical adipose tissue depots of palms, soles, orbits, and under the scalp is preserved or not (6) and other comorbidities can be observed (7).

BSCL is classified in four different subtypes (8); BSCL type 1 is an autosomal recessive disease due to variants (9) of the gene coding for the enzyme 1-acylglycerol-3phosphate-Oacyltransferase $\beta$ (lysophosphatidic acid acyltransferase beta or AGPAT2 OMIM\# 608594). BSCL type 2 is caused by biallelic mutations in BSCL2 encoding seipin, a transmembrane protein involved in the functional relationships between endoplasmic reticulum and lipid droplets [OMIM\# 269700) (10)]. Rarer forms of BSCL are due to mutations of the CAV1 (OMIM\# 612526) and PTRF (OMIM\# 613327) genes $(11,12)$, respectively, encoding caveolin-1 and cavin-1, belonging to the signaling platforms caveolae at the plasma membrane.

AGPAT2 is a lysophosphatidic acid acyltransferase isoform of 278 amino acids localized in the endoplasmic reticulum and highly expressed in white adipocytes (13). It catalyzes the transformation of lysophosphatidic acid (1,2-diacylglycerol3phosphate) into phosphatidic acid (glycerol-3-phosphate) which belongs to the glycerophospholipid and triglyceride biosynthetic pathways. AGPAT2 deficiency leads to a depletion of triglycerides inside the adipose organ and to a defective signaling of key elements such as PI3K/AKT and PPAR $\gamma$ involved in proper adipogenesis (14). AGPAT2 KO mice develop a phenotype resembling that of BSCL type 1 (BSCL1) in humans characterized by near total loss of white and brown adipose tissue with severe insulin resistance, diabetes, and hepatic steatosis (15).

\footnotetext{
Abbreviations: BSCL, Berardinelli-Seip congenital lipoatrophy; AGPAT2, 1acylglycerol-3phosphate-O-acyltransferase $\beta$; PI3K, phosphoinositide 3-kinase; $\mathrm{AKT}$, serine/threonine-protein kinases; OMIM, online mendelian inheritance in man; PPAR $\gamma$, peroxisome proliferator-activated receptor gamma; CAV1, caveolin-1; PTRF, polymerase I and transcript release factor; $\mathrm{KO}$, knockout mouse; AST, aspartate aminotransferase; ALT, alanine aminotransferase; ExAC, exome aggregation consortium; HDL, high density lipoprotein-cholesterol; ECG, electrocardiogram; HbAlc, glycated hemoglobin; LH, luteinizing hormone; FSH, follicle-stimulating hormone; E2, estradiol; IGF-1, Insulin-like growth factor1; DEXA, dual-energy x-ray absorptiometry; FT3, free tri-iodothyronine; CLIA, chemiluminescence immunoassay; FT4, free thyroxine; TSH, thyroid stimulating hormone; ICMA, chemiluminescent immunochemiluminometric assay; PRL, prolactin; GGT, gamma-glutamyl transferase; PCR, polymerase chain reaction; dbSNP, Single Nucleotide Polymorphism Database.
}

A very relevant aspect of the disease is the increased food intake caused by reduced circulating levels of the adipose-derived hormone leptin (16), which contributes to the metabolic alterations.

BSCL is a very rare disorder, its prevalence was estimated to be $1-10$ case every 10 million $(3,17)$, although it could reach 3 per 100,000 people in some areas (18). Some of the mutations recur in specific geographic areas, probably due to a "founder effect" (19), and their presence is unveiled by consanguineous and endogamic marriages or in small and isolated communities.

Close to $95 \%$ of patients affected by BSCL have identified mutations (19). BSCL1 is an autosomal recessive disease and all patients exhibit either homozygous or compound heterozygous AGPAT2 mutations. Most reported mutations are nonsense or cause altered splicing or frame shifts, which disrupts the protein activity. Only few missense mutations have been so far described.

\section{CASE REPORT \\ Clinical Case $\mathrm{N}^{\circ} 1$}

A 7 years-old child was referred to our Lipodystrophy Center. The boy was born at term after an uneventful pregnancy. His birth weight was $3.250 \mathrm{Kg}$. He was the third child of non-consanguineous healthy parents living in a small village in the Northern part of Italy. At the age of 3 months, he was admitted to hospital for vomiting and diarrhea. Physical examination showed a generalized lack of subcutaneous fat, abdominal distension, muscle hypertrophy, low anterior hairline, prominent orbital ridges, large ears, and umbilical hernia (Figure 1). Laboratory tests showed severe hypertriglyceridemia $(1565 \mathrm{mg} / \mathrm{dl})$ and increased liver enzymes (AST $543 \mathrm{U} / \mathrm{L}, \mathrm{ALT}$ $667 \mathrm{U} / \mathrm{L}$ ), breast feeding was halted and low fat medium chain triglycerides enriched milk was introduced with progressive normalization of the parameters. Liver ultrasound showed diffuse hyperechogenicity consistent with steatosis. BSCL1 syndrome was diagnosed when genetic analysis revealed a novel nonsense homozygous AGPAT2 pathogenic variant. In this patient a nucleotide change (c.430 C $>\mathrm{T}$ ) was observed in exon 3 of the AGPAT2 gene predicting the substitution of the Glutamine residue at position 144 by a stop codon (p.Gln144*). This variant was not found in the ExAC nor in the 1,000 genome project databases and has never been described in patients affected by BSCL1. In silico analysis confirmed the high pathogenic score of the mutation. The allelic variant in the heterozygous form was found in both asymptomatic parents and in three additional family members of the maternal side (Figure 1).

A low-fat hypocaloric diet was then prescribed. At the time we first evaluated the patient (at 7 years of age) his development and school performance were appropriate for age. On physical examination his height and weight were between the 25th and 50th percentile of the growth charts. He was prepubertal. Lipoatrophy affected the entire body with the exception of the palm of the hands and sole of the feet. He presented muscle hypertrophy, particularly of the calf and thigh muscles (Figure 1). On low fat diet, biochemical analysis showed normal levels of fasting blood glucose, triglycerides, total cholesterol, and liver enzymes. He had low level of 
A
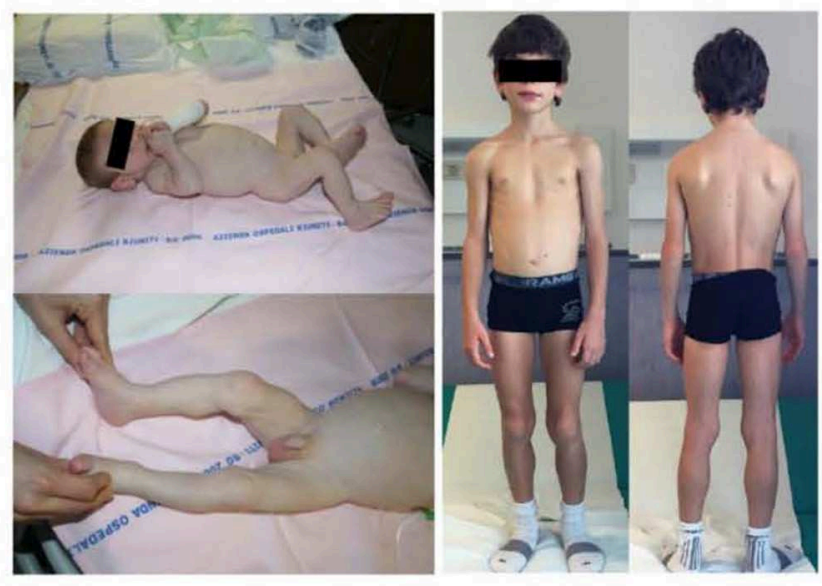

C
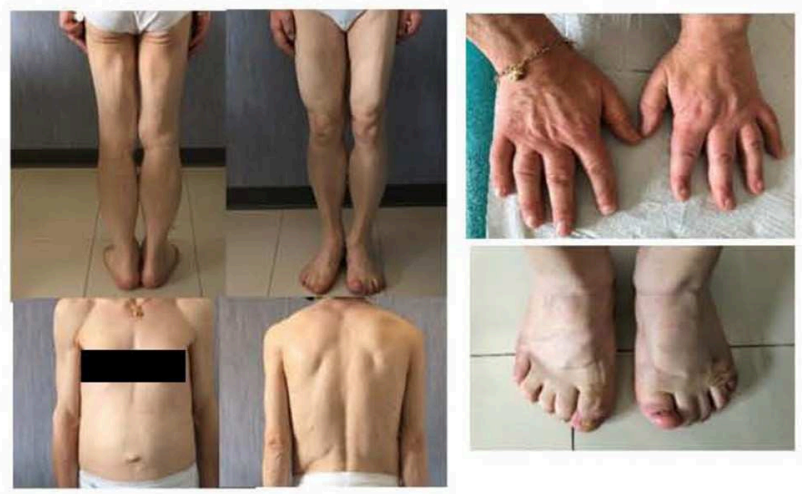

B
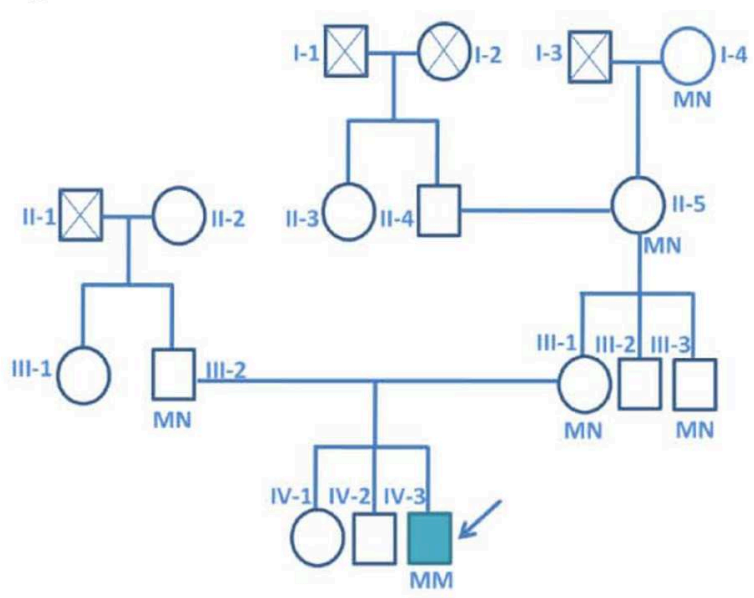

D

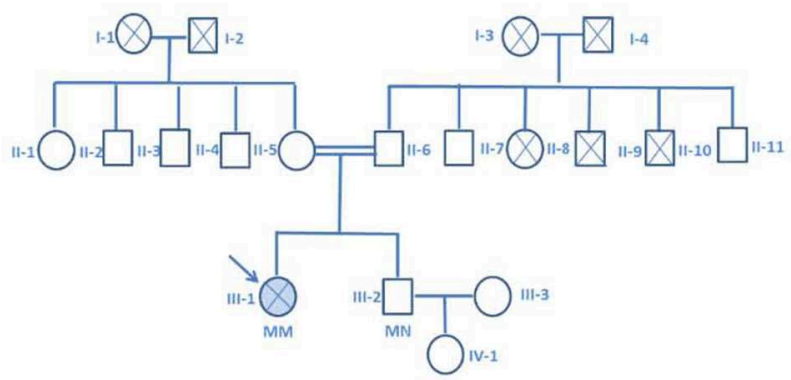

FIGURE 1 | Pictures and family pedigrees of the probands. (A) Pictures of Proband 1 at 4 months of age (left) and at close to 9 years of age (right). (B) pedigree of the family of the proband affected by a novel nonsense homozygous pathogenic variant (p.Gln144*) in exon 3 of the AGPAT2 gene. (C) Pictures of the proband number 2 and particular of the enlarged hands and feet. (D) pedigree of the family of the proband affected by a novel nonsense homozygous variant (Arg159Cys) in exon 3 of the AGPAT2 gene; parents of the index case were second degree cousins (I-2 and I-4 were first degree cousins). The probands are indicated with the arrow, circles indicate male subjects, squares female subjects. Roman numbers specify the different generations while Arabic numbers identify different subjects. Double horizontal line indicate consanguinity. M, mutant allele; N, normal allele. Filled symbol indicate the presence of the disease, crossed symbols indicate deceased individuals.

high density lipoprotein-cholesterol (HDL-cholesterol $28 \mathrm{mg} / \mathrm{dl}$ ). As expected from the generalized lack of body fat, serum leptin levels were very low $(0.1 \mathrm{ng} / \mathrm{ml})$. Fasting insulin $(4.4$ $\mathrm{mU} / \mathrm{L})$ and glycated hemoglobin levels $(33 \mathrm{mmol} / \mathrm{mol})$ were in the normal range. Endocrinological evaluation showed normal thyroid, adrenal and pituitary functions. No pathological findings were demonstrated at cardiologic evaluation (ECG and echocardiography). Abdominal ultrasonography revealed mild steatosis. The hepatic left lobe volume, a standardized surrogate marker of liver volume (20), was enlarged (234 ml). Liver stiffness value assessed by fibroscan was normal $(3.7 \mathrm{kPa})$.

\section{Clinical Case $\mathbf{N}^{\circ} \mathbf{2}$}

The second patient was a 53 years old woman born from consanguineous parents (second-degree cousins, Figure 1) living in a 200 residents village located in the Center of Italy. At 10 years, after development of polyuria and polydipsia she was diagnosed with lipoatrophic diabetes and eruptive xanthomatosis (triglycerides $=718 \mathrm{mg} / \mathrm{dl}$ ). The patient was advised initially to restrict dietary fats and carbohydrate intake, but over the years she developed uncontrolled hyperglycemia and hyperphagia briefly treated with fenfluramine that exacerbated a bipolar disorder. Later on anti-hypertensive therapy (at age 40) and insulin therapy (at age 43), where administered after she had already developed bilateral proliferative retinopathy and blindness of the left eye because of retinal detachment. At 44 years, she was diagnosed with diabetic and hypertensive nephropathy. She had irregular periods (oligo-menorrhea) throughout her life and no pregnancies. She went into menopause at age of 49 .

At the time we first evaluated the patient (53 years of age), physical examination (Figure 1) revealed diffuse reduction of subcutaneous fat, acromegaloid features (marked prognathism and enlarged hands and feet), acanthosis nigricans on the neck 
and axillae. In addition, she displayed muscle hypertrophy, phlebomegaly and umbilical hernia. No signs of hirsutism were present. The height and the body mass index of the patient were $1.55 \mathrm{~m}$ and $22.1 \mathrm{~kg} / \mathrm{m}^{2}$, respectively.

Biochemical blood tests, under insulin treatment (51 IU/day) and omega three fatty acids, showed high levels of fasting plasma glucose with normal glycated hemoglobin (178 mg/dl; HbAlc $37 \mathrm{mmol} / \mathrm{mol}$, respectively) and frequent hypoglycemic episodes, hypertriglyceridemia (423 mg/dl), and low HDL-cholesterol levels $(22 \mathrm{mg} / \mathrm{dl})$. Serum creatinine and proteinuria were 2.14 $\mathrm{mg} / \mathrm{dl}$ and $1.9 \mathrm{~g} / 24 \mathrm{~h}$, respectively. Endocrinological evaluation showed normal thyroid, parathyroid, and adrenal functions. Plasma leptin and adiponectin were severely reduced $(0.4 \mathrm{ng} / \mathrm{ml}$ and $0.1 \mathrm{mcg} / \mathrm{ml}$, respectively). Gonadal function showed low levels of gonadotropins with undetectable estradiol (LH 1.1 UI/l; FSH $4.6 \mathrm{UI} / \mathrm{l} ; \mathrm{E} 2<20 \mathrm{ng} / \mathrm{L}$ ) and slightly increased levels of IGF-1 $(231 \mathrm{mcg} / \mathrm{L})$ and prolactin $(71.4 \mathrm{mcg} / \mathrm{l})$. Pituitary imaging excluded the presence of adenomas or suprasellar masses and hyperprolactinemia was attributed to the chronic treatment with risperidone.

Abdominal ultrasonography revealed mild liver steatosis with an enlarged hepatic left lobe volume $(223 \mathrm{ml})$ and splenomegaly. Body composition assessed by DEXA showed reduced total fat mass $(9.2 \%)$. Total body X-rays confirmed the presence of multiple bone cysts, confluent, with osteosclerotic appearance, mainly localized in the femoral heads and humerus diaphysis.

Her cardiovascular evaluation showed hypertension, dilated left atrial chamber, left ventricular hypertrophy but normal ventricular volume. Taking into account the high cardiovascular risk of this patient, a stress myocardial perfusion SinglePhoton Emission Computed Tomography (SPECT) SPECT was conducted with negative results. The patient had been asymptomatic during the stress test.

Approximately 3 months after discharge from our institution, she experienced chest pain and was admitted to the emergency room and diagnosed with massive myocardial infarction and acute heart failure. Despite transcutaneous revascularization for diffuse coronary stenosis the patient developed progressive cardiac insufficiency and kidney failure. One month after her hospitalization the patient died in the intensive care unit.

In this patient, genetic screening of the AGPAT2 gene revealed a homozygous gene variant predicting the substitution of the Arginine residue at position 159 with a Cysteine (p.Arg159Cys, nucleotide change c. $475 \mathrm{C}>\mathrm{G})$.

The missense variant p.Arg159Cys (Figure 2) in exon 3 of the gene was found, among others, in the ExAC database with an allelic frequency of 0.00553 and in the 1,000 Genome Project with an allelic frequency of 0.003 in the general population. In silico analysis showed a high pathogenic score (180/215). This aminoacid is significantly conserved (Figure 2) among different species and resides in a highly conserved protein region. Protein stability of the missense variant p.Arg159Cys may be affected as predicted by dedicated software. This variant was found in the heterozygous state in her brother (Figure 1) who had normal triglycerides, glucose tolerance, glycated hemoglobin, hepatic ultrasound, and total body fat assessed by DEXA.

\section{Biochemistry and Hormones}

All determinations were carried out after $12 \mathrm{~h}$ fasting. Leptin and adiponectin were measured by CLIA from Mediagnost, Reutlingen, Germany, FT3 (CLIA), FT4 (CLIA), TSH (ICMA) from Ortho Clinical Diagnostic Rochester NY, USA, FSH (ICMA), PRL (ICMA), LH (ICMA), Insulin (ICMA) from Beckman Coulter, Inc. Diagnostics California, USA, and IGF1 (ICMA) from Immunodiagnostic Systems Holdings, UK. Glucose cholesterol, triglycerides, creatinine, AST, ALT, GGT, were determined using automated equipment at the central Laboratory of the University Hospital of Cisanello, Italy.

\section{Genetic Testing, Mutation Screening}

AGPAT2 variants were identified by next generation sequencing (Patient 1) and/or Sanger sequencing (Patient 2), and all were confirmed by Sanger sequencing in an independent DNA sample. Specific primers were designed to amplify AGPAT2 exons and splice junctions from genomic DNA, isolated from whole blood. PCR was performed using PCR Master Mix (Promega Corporation, WI 53711-5399) with an annealing temperature of $60^{\circ} \mathrm{C}$. After purification with ExoProStar (GE Healthcare UK Limited, UK), the PCR products were directly sequenced using Applied Biosystems $3130 \mathrm{xl}$ sequencer (Thermo Fisher Scientific, MA, USA).

\section{In silico Modeling of the Pathogenicity of AGPAT2 Variants}

In silico analysis was conducted using Mutationtaster software [http://mutationtaster.org/ (Last time accessed December 23, 2019)]: each variant is given a score up to the value of 215; a high score is indicative for pathogenic mutations. ExAC and 1,000 Genome Project, dbSNP, Ensembl, Exome Variant server, and in the Clinvar database databases were also searched to determine allelic frequencies in the general population. PROVEAN (Protein Variation Effect Analyzer) is a software tool which predicts whether an amino acid substitution or indel has an impact on the biological function of a protein (http://provean.jcvi.org/index. php, last time accessed December 23, 2019). DUET a server for predicting effects of mutations on protein stability via an integrated computational approach (http://biosig.unimelb.edu. au/duet/stabilityn, last time accessed December 23, 2019) was also used. Prediction from SIFT, Mutation Assessor, CAD and Revel were obtained from the Ensembl genome database.

\section{DISCUSSION}

BSCL1 pathogenic mutations affect triacylglycerol and glycerophospholipid synthesis in adipose tissue and cause lipodystrophy by impairing adipogenesis and depleting the adipocytes of triglycerides $(9,14)$.

Patients with BSCL1 are either homozygous or compound heterozygous for AGPAT2 gene mutations that co-segregate with the phenotype of disease in accordance with an autosomal recessive pattern of inheritance. Heterozygotes carriers are 


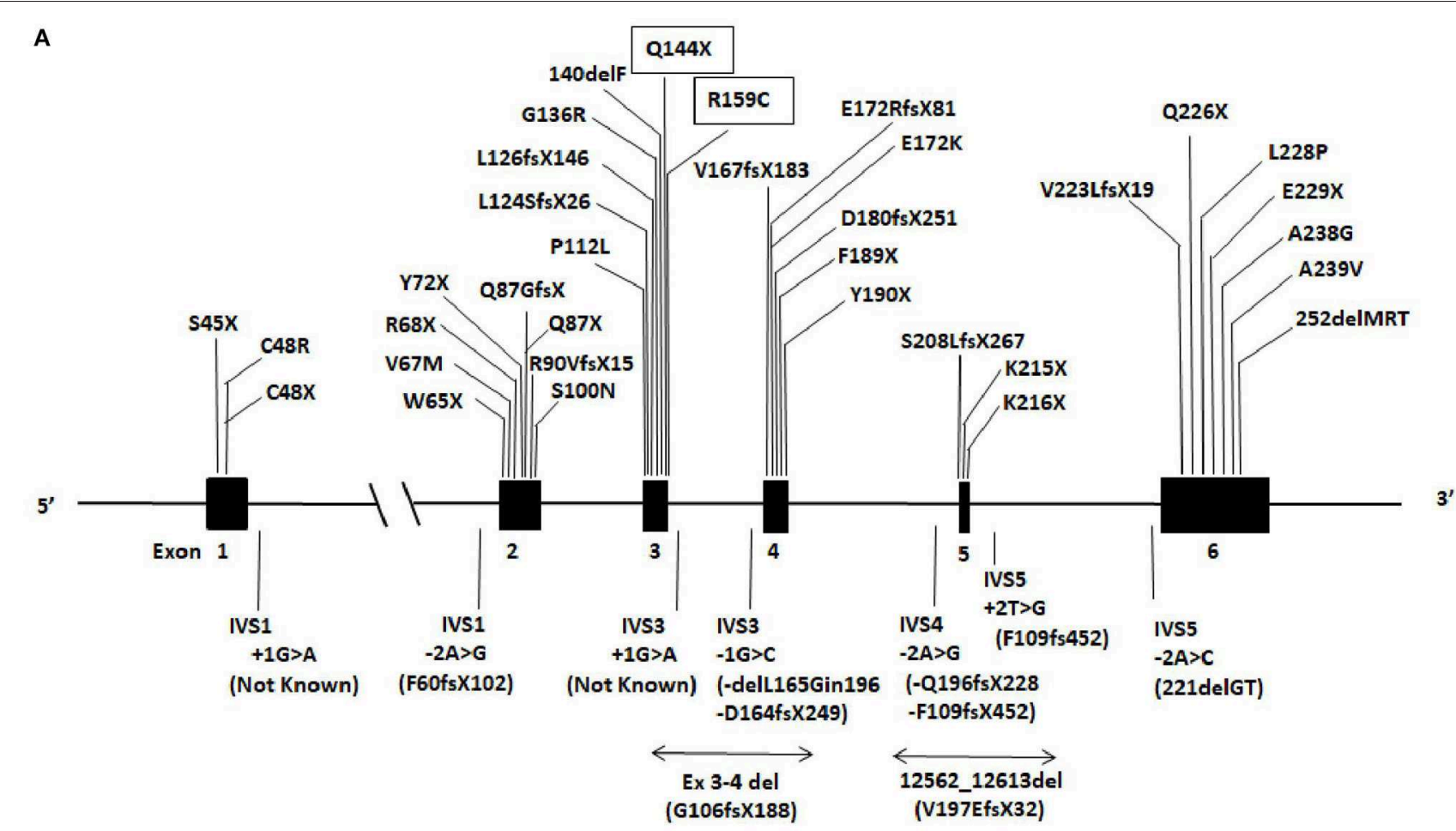

B TAM T V MAD L GE C M V R EN LK V W IY

Human TAMT VMADLGERMVRENLKVWIY

Ptroglodytes $\quad{ }^{87}$ TAM T VMAD L GERMVREN L K V W I Y

149

Macaca Mulatta TAM T V MADL GERM VRE N L K V W I Y

Felix Catus TAM T V MA D V G E R M V R E N L K V W VY

Mus Musculus ${ }^{148}$ TAM S V MA D L G D L M V K E N L K V W I Y

FIGURE 2 | AGPAT2 gene variants described so far and sequence alignment of patient number 2. (A) Schematic gene structure of AGPAT2 gene, filled boxes indicate exons and in between lines introns: various mutations of AGPAT2 described so far, novel mutations described in this manuscript are inscribed in rectangular boxes (upper panel). (B) Lower panel indicate AGPAT2 aminoacid sequence alignment in humans and other mammalians. The arrow points at the position of the missense variant at arginine residue 159 (p.Arg159Cys) found in patient number 2 which resides in a highly conserved region.

asymptomatic although an increased incidence of diabetes is suggested (21).

We have identified 150 cases of patients with a genetically confirmed BSCL1 syndrome reported and 42 different mutations. Most of the mutations cause frame-shifts or alter mRNA splicing leading to the synthesis of a non-functional enzyme while rarer pathogenic variants cause amino acid substitutions (Tables 1, 2). Mutations are spread throughout all six exons and intronic junctions of the gene (Figure 2). Approximately $1 / 4$ of the mutations are nonsense mutations, more frequently present in exon 2 and 3. Insertions and deletions localize usually in exons 3 and 4 while over $80 \%$ of mutations altering mRNA splicing localize in intron 4 (p.Gln196fsX228 or p.Phe109fsX452 variants). Fewer patients (15\%) present a compound heterozygosity for AGPAT2 pathogenic variants and each compound mutation, concentrating predominantly in introns or exons 3 or 4 , is almost unique. No relationships between AGPAT2 pathogenic genotypes and the severity of lipodystrophy or specific complications has ever been described. 
TABLE 1 | Pathogenic variants of AGPAT2 gene described in the homozygote state.

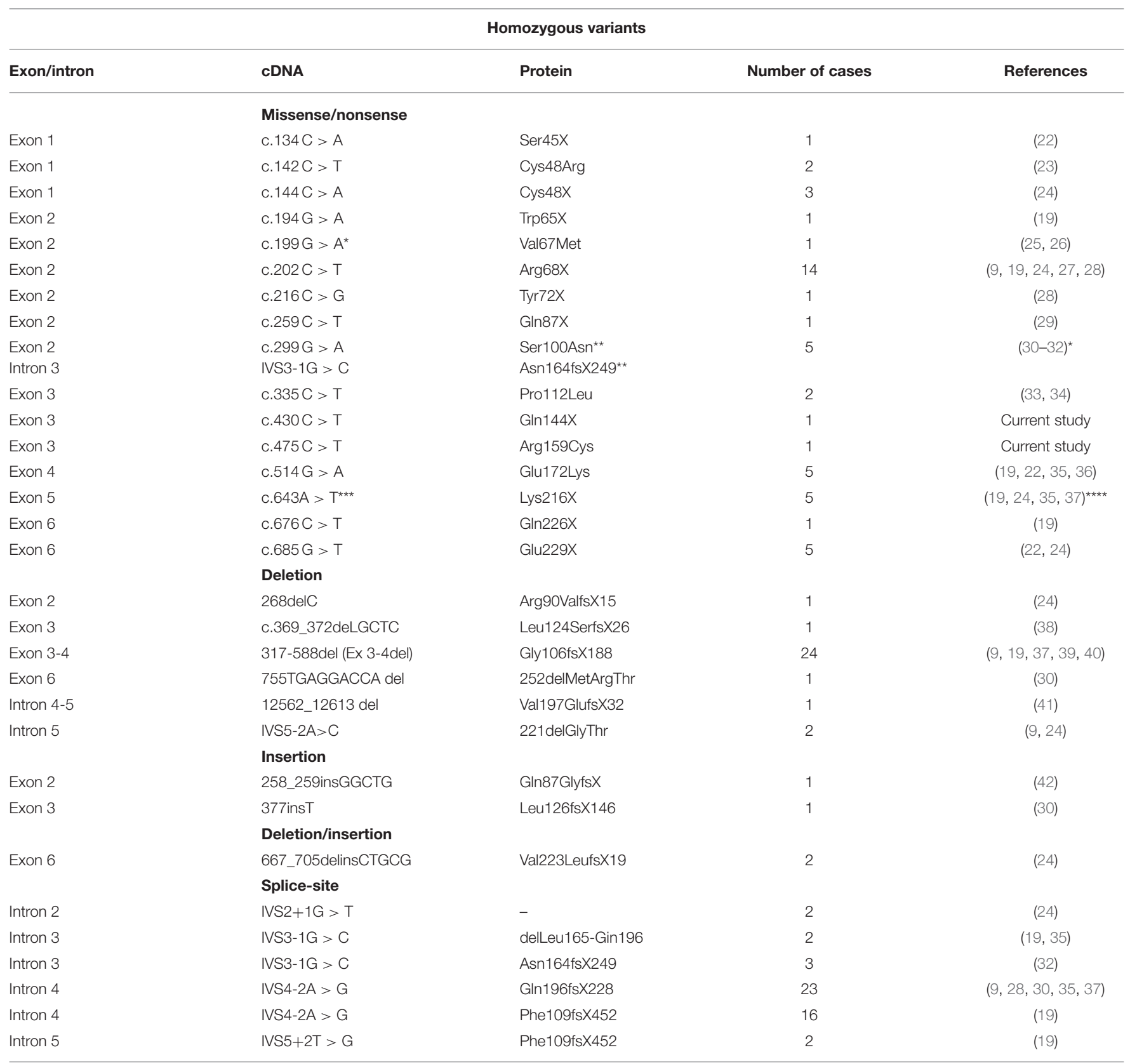

*Originally described as c.119 G > A. ${ }^{* \star D}$ Double homozygosity. ${ }^{* \star \star}$ Originally described as $712 \mathrm{~A}>\mathrm{T} .{ }^{\star \star \star \star}$ Originally described as $645 \mathrm{~A}>\mathrm{T}$.

Several are the metabolic complications related to AGPAT2 functional loss, insulin resistance is a hallmark of the disease and usually progresses during childhood (4) leading to diabetes mellitus after adolescence.

In the functional absence of AGPAT2, liver activity of the isoform 1 of the enzyme (AGPAT1) is significantly upregulated leading to overproduction of diacylglycerol, used for triacylglycerol synthesis (15). This could be an additional mechanism responsible for the development of severe liver steatosis and hepatomegaly besides the ectopic accumulation of triglycerides of alimentary origin.
Patients with BSCL1 display specific skeletal abnormalities, in particular lytic lesions at the extremities of appendicular bones associated with a diffuse serous transformation of the bone marrow (35), which can help clinicians with an early diagnosis in pauci-symptomatic patients.

Many patients with generalized lipodystrophy show evidence of cardiac hypertrophy, as measured by echocardiographic parameters. Lupsa et al. (45) have documented that out of 19 patients affected by BSCL1, 10 had some evidence, in some cases severe, of left ventricular hypertrophy. ECG abnormalities were seen in $53 \%$ of patients. 
TABLE 2 | Pathogenic variants of AGPAT2 gene in the compound heterozygous state.

\begin{tabular}{|c|c|c|c|c|}
\hline \multicolumn{5}{|c|}{ Compound heterozygote variants } \\
\hline Exon & cDNA & Protein & Number of cases & References \\
\hline $\begin{array}{l}\text { Exon } 2 \\
\text { Intron } 4\end{array}$ & $\begin{array}{l}202 C>T \\
\text { IVS4-2A > G }\end{array}$ & $\begin{array}{l}\text { Arg68X } \\
\text { Gln196fsX228 }\end{array}$ & 2 & (43) \\
\hline $\begin{array}{l}\text { Exon3 } \\
\text { Intron } 4\end{array}$ & $\begin{array}{l}\text { c.369_372delGCTC } \\
\text { IVS4-2A > G }\end{array}$ & $\begin{array}{l}\text { Leu124SerfsX26 } \\
-\end{array}$ & 1 & (38) \\
\hline $\begin{array}{l}\text { Exon } 3 \\
\text { Exon } 4\end{array}$ & $\begin{array}{l}\text { 406G >A } \\
\text { 504delGA }\end{array}$ & $\begin{array}{l}\text { Gly136Arg } \\
\text { Val167fsX183 }\end{array}$ & 1 & (9) \\
\hline $\begin{array}{l}\text { Exon } 3 \\
\text { Intron } 4\end{array}$ & $\begin{array}{l}\text { 418delTTC } \\
\text { IVS4-2A > G }\end{array}$ & $\begin{array}{l}\text { 140delPhe } \\
\text { Gln196fsX228 }\end{array}$ & 1 & (9) \\
\hline $\begin{array}{l}\text { Exon } 3 \\
\text { Intron } 4\end{array}$ & $\begin{array}{l}\text { 377insT } \\
\text { IVS4-2A > G }\end{array}$ & $\begin{array}{l}\text { Leu126fsX146 } \\
\text { Gln196fsX228 }\end{array}$ & 2 & (9) \\
\hline $\begin{array}{l}\text { Exon } 3 \\
\text { Intron } 4\end{array}$ & $\begin{array}{l}355 C>T \\
\text { IVS4-2A }>G\end{array}$ & $\begin{array}{l}\text { Pro112Leu } \\
\text { Gln196fsX228 }\end{array}$ & 1 & (43) \\
\hline $\begin{array}{l}\text { Exon } 4 \\
\text { Exon } 5\end{array}$ & $\begin{array}{l}\text { c.513del C } \\
\text { c.622_626TCСTC }\end{array}$ & $\begin{array}{l}\text { Glu172ArgfsX81 } \\
\text { Ser208LeufsX267 }\end{array}$ & 1 & (44) \\
\hline $\begin{array}{l}\text { Exon } 4 \\
\text { Intron } 1\end{array}$ & $\begin{array}{l}\text { 538Gdel } \\
\text { IVS1+1G > A }\end{array}$ & $\begin{array}{l}\text { Asp180fsX251 } \\
-\end{array}$ & 1 & (30) \\
\hline $\begin{array}{l}\text { Exon } 4 \\
\text { Intron } 3\end{array}$ & $\begin{array}{l}\text { c. } 636 C>A \\
\text { IVS3-1G }>C\end{array}$ & $\begin{array}{l}\text { Phe189X } \\
\text { Asn164fsX249 }\end{array}$ & 1 & (37) \\
\hline $\begin{array}{l}\text { Exon } 4 \\
\text { Intron } 4\end{array}$ & $\begin{array}{l}570 \mathrm{C}>\mathrm{A} \\
\text { IVS4-2A }>\mathrm{G}\end{array}$ & $\begin{array}{l}\text { Tyr190X } \\
\text { Gln196fsX228 }\end{array}$ & 2 & (30) \\
\hline $\begin{array}{l}\text { Exon } 6 \\
\text { Intron } 4\end{array}$ & $\begin{array}{l}683 \mathrm{~T}>\mathrm{C} \\
\text { IVS4-2A > G }\end{array}$ & $\begin{array}{l}\text { Leu228Pro } \\
\text { Gln196fsX228 }\end{array}$ & 2 & (9) \\
\hline $\begin{array}{l}\text { Exon } 6 \\
-\end{array}$ & $\begin{array}{l}\text { c. } 712 C>G \\
-\end{array}$ & $\begin{array}{l}\text { Ala238Gly } \\
\text { - }\end{array}$ & 1 & (19) \\
\hline $\begin{array}{l}\text { Exon } 6 \\
\text { Exon 6- } \\
\text { 3'UTR }\end{array}$ & $\begin{array}{l}716 C>T \\
c .916 C>G\end{array}$ & $\begin{array}{l}\text { Ala239Val } \\
-\end{array}$ & 1 & (9) \\
\hline $\begin{array}{l}\text { Intron } 1 \\
-\end{array}$ & $\begin{array}{l}\text { IVS1-2A > G } \\
-\end{array}$ & $\begin{array}{l}\text { Phe60fsX102 } \\
-\end{array}$ & 1 & (19) \\
\hline $\begin{array}{l}\text { Intron } 4 \\
\text { Intron } 3\end{array}$ & $\begin{array}{l}\text { IVS4-2A }>G \\
\text { IVS3+1G }>A\end{array}$ & $\begin{array}{l}\text { Gln196fsX228 } \\
-\end{array}$ & 1 & (30) \\
\hline $\begin{array}{l}\text { Intron } 4 \\
-\end{array}$ & $\begin{array}{l}\text { IVS4-2A > G } \\
-\end{array}$ & $\begin{array}{l}\text { Phe109fsX452 } \\
\text { - }\end{array}$ & 2 & (19) \\
\hline
\end{tabular}

At variance with the numerous cardiovascular risk factors displayed by patients with congenital generalized lipodystrophy (46), myocardial infarction and sudden death were not reported to be the leading cause of decease (47).

The two cases presented illustrate well the clinical heterogeneity of BSCL1. In the younger patient, born from non-consanguineous parents, the metabolic complications, at the age of 8 years, were mild and controlled by hypocaloric diet and physical activity. The older woman, who was diagnosed during puberty, showed the multiple and severe metabolic derangements typically occurring in the natural history of the disease. Regarding the cardiac health, ECGs in both our patients were normal but echocardiography revealed dilated left atrial chamber and left ventricular hypertrophy in the adult patient, who also had hypertension. Taking into account the numerous and long standing cardiovascular risk factors of this 53 years old woman, we performed one of the most accurate test available for diagnosing coronary artery disease, which, however, failed to foresee the underlining ischemic disease. The etiology of the frequent hypertrophic cardiomyopathy in lipodystrophy remains unclear; in part, it could be related to the underlying hypertension, but also to the increased growth stimulatory action of excess insulin (48). A third potential mechanism of cardiac disease is related to the increased fatty acid influx or ectopic deposition of fat in the myocardium. "Lipotoxic cardiomyopathy" in lipodystrophy has not proved yet but is a very plausible explanation since a significant number of patients develop cardiac hypertrophy and left ventricular dysfunction in the absence of hypertension (45). Lipotoxic cardiomyopathy, together with the vascular complications of diabetes, hypertension and dyslipidemia, favor cardiovascular morbidity and mortality (46). Retrospectively, the adoption of an insulin treatment favoring hypoglycemic episodes rather than insulin sensitizers and drugs with a protective cardiovascular profile may have been further detrimental in this case. Furthermore, the role for implementation of a protective cardiac treatment (ace-inhibitors, anti-aldosterone drugs, anti-aggregants, PCSK9 inhibitors) should be assessed in adult patients with BSCL. 
Another consequence of chronically decreased leptin levels is the reduction of $\mathrm{GnRH}$ pulsatile activity which causes oligomenorrhea (4). Indeed, our patient presented with a clinical history of oligo-menorrhea and showed almost undetectable gonadotropin levels, probably determined by the combination of reduced leptin levels and iatrogenic hyperprolactinemia. Notably, $\sim 10 \%$ of BSCL1 patients, display cognitive impairment (49), but our patients did not.

Described individuals with mutations in the AGPAT2 gene mainly originated from America or Northern Europe and occasionally from sub-Saharan Africa or Middle Eastern Countries (50). As for Caucasian Italian population the two herein described subjects add up to one other single case previously reported (33).

The first mutation (p.Gln $144^{*}$ ) is not present in databases collecting variants identified in the general population.

In this case it is straightforward to predict that the mutation affects the protein activity via the synthesis of a truncated enzyme approximately half (143 amino acids) of the proper size. Missense mutations located close (p.Gly136Arg) (9) or nonsense mutations more distal to the C-terminal part of the protein have been previously reported as pathogenic (e.g., p.Phe189X, p.Tyr190X, p.Lys216X, p.Gln226X) (19, 30, 37).

The substitution of the Arginine residue at position 159 with a Cysteine (AGPAT2 p.Arg159Cys) was present in the homozygous state in Proband 2 and found in the heterozygous state in the unaffected brother. This variation alters a conserved amino acid site in a highly conserved region among mammalian species and its in silico score was predictive of disruption of protein activity. Furthermore, the homozygous variant segregated with the disease in the family making its pathogenic role possible.

We speculate that the substitution of hydrophilic charged Arginine with a polar, non-charged Cysteine, capable of forming disulfide bonds may disrupt the folding or activity of the enzyme. Results from dedicated software tools are not fully concordant in this regard: SIFT, Mutation Assessor, CAD, and PROVEAN predict in fact the aminoacid change to be neutral whereas Revel consider this substitution pathogenic, in line with the reduced stability of the R159C variant predicted by DUET, an integrated computational approach that takes into account the three dimensional structure of the protein.

Databases collecting variants existent in the general population report the heterozygous p.Arg159Cys to be present at a frequency around $0.3 \%$ which is higher than expected from the disease prevalence. The presence of few homozygous carriers (three subjects in $\mathrm{ExaC}$ and nine subjects in gnomAD) is reported by these databases but no information regarding the clinical history of the homozygous subjects can be retrieved. This evidence is difficult to reconcile with our findings. We therefore cannot rule out different pathogenic mechanisms. Pathogenic AGPAT2 missense mutations are thought to reduce protein expression (23) and possibly enzymatic activity (27). Testing in vitro the effects of the described mutation may give us further clues, but the assessment of the pathogenic potential of AGPAT2 variants has been proven challenging and has been rarely performed $(23,27)$.
Berardinelli Seip syndrome is frequently unveiled by consanguineous marriages or in small and relatively isolated communities (50). This was indeed the case for both patients. The first one was born from apparently unrelated parents living in a small village of few thousands inhabitants. The occurrence of a unique variant of AGPAT2 was found in members on both sides of the family, suggesting a founder effect from a common ancestor. The second patient was born from second-degree cousins.

In conclusion we describe two patients with BSCL type 1 lipodystrophy harboring novel homozygous variants. The first one presented with a null variant (p.Gln144*) occurring in exon 3 of AGPAT2 gene. The second patient presented with a homozygous AGPAT2 missense variant (p.Arg159Cys), never described previously in BSCL1 patients, raising the question on its pathogenicity. The segregation of the disease with the genotype in the family and the in silico analysis are compatible with a causative role of the p.Arg159Cys variant.

We remark that BSCL1 can be clinically very heterogeneous at presentation and that the associated complications, occurring in the natural history of the disease, may reduce lifeexpectancy. We point to the necessity for medical treatments capable of reducing the risk of cardiovascular death. In BSCL1 patients, the assessment of cardiovascular disease with conventional diagnostic means maybe particularly challenging. Future studies will be essential to investigate if specific cardiovascular diagnostic approach is recommended in adult BSCL patients.

\section{DATA AVAILABILITY STATEMENT}

All datasets generated for this study are included in the article.

\section{ETHICS STATEMENT}

Written informed consent to participate in this study was provided by the participants' legal guardian/next of kin. Written informed consent was obtained from the individual(s), and minor(s)' legal guardian/next of kin, for the publication of any potentially identifiable images or data included in this article.

\section{AUTHOR CONTRIBUTIONS}

GC, SM, FF, and FS carried out the characterization of the patients. CP, MS, GS, MM, and OL performed the genetic studies of AGPAT2 gene. GC, SM, and FS wrote the manuscript. IJ and $\mathrm{CV}$ reviewed and edited the manuscript. All authors read and approved the final version of the manuscript.

\section{FUNDING}

This research was funded by the Italian Ministry of the University, Project code 2015JSWLTN: Metabolic flexibility and ectopic fat. Adiposity phenotype, mitochondrial dysfunction, hepatic inflammation, gut microbiota, cardiac failure, and genetics for a comprehensive understanding of the cross-talk 
among adipose tissue, liver, and musculo-skeletal system. IJ, OL, and CV were supported by Assistance Publique-Hôpitaux de Paris, Sorbonne Université, Institut National de la Santé et de la Recherche Médicale (Inserm), Institut Hospitalo-Universitaire de Cardiométabolisme et Nutrition (ICAN), and Fondation pour la Recherche Médicale, Paris, France.

\section{REFERENCES}

1. Berardinelli W. An undiagnosed endocrinometabolic syndrome: report of 2 cases. J Clin Endocrinol Metab. (1954) 14:193-204. doi: 10.1210/jcem-14-2-193

2. Seip M. Lipodystrophy and gigantism with associated endocrine manifestations. A new diencephalic syndrome? Acta Paediatr Scand. (1959) 48:555-74. doi: 10.1111/j.1651-2227.1959.tb17558.x

3. Garg A. Acquired and inherited lipodystrophies. N Engl J Med. (2004) 350:1220-34. doi: 10.1056/NEJMra025261

4. Garg A. Lipodystrophies: genetic and acquired body fat disorders. J Clin Endocrinol Metab. (2011) 96:3313-25. doi: 10.1210/jc.2011-1159

5. Capeau J, Magré J, Caron-Debarle M, Lagathu C, Antoine B, Béréziat V, et al. Human lipodystrophies: genetic and acquired diseases of adipose tissue. Endocr Dev. (2010) 19:1-20. doi: 10.1159/000316893

6. Simha V, Garg A. Phenotypic heterogeneity in body fat distribution in patients with congenital generalized lipodystrophy caused by mutations in the AGPAT2 or seipin genes. J Clin Endocrinol Metab. (2003) 88:5433-7. doi: 10.1210/jc.2003-030835

7. Akinci B, Meral R, Oral EA. Phenotypic and genetic characteristics of lipodystrophy: pathophysiology, metabolic abnormalities, and comorbidities. Curr Diab Rep. (2018) 18:143. doi: 10.1007/s11892-018-1099-9

8. Araújo-Vilar D, Santini F. Diagnosis and treatment of lipodystrophy: a step-by-step approach. J Endocrinol Invest. (2018) 42:61-73. doi: 10.1530/endoabs.56.S20.3

9. Agarwal AK, Arioglu E, De Almeida S, Akkoc N, Taylor SI, Bowcock $\mathrm{AM}$, et al. AGPAT2 is mutated in congenital generalized lipodystrophy linked to chromosome 9q34. Nat Genet. (2002) 31:21-3. doi: 10.1038/ ng880

10. Magré J, Delépine M, Khallouf E, Gedde-Dahl T Jr, Van Maldergem L, Sobel E, et al. Identification of the gene altered in Berardinelli-Seip congenital lipodystrophy on chromosome 11q13. Nat Genet. (2001) 28:36570. doi: $10.1038 /$ ng585

11. Kim CA, Delépine M, Boutet E, El Mourabit H, Le Lay S, Meier M, et al. Association of a homozygous nonsense caveolin-1 mutation with BerardinelliSeip congenital lipodystrophy. J Clin Endocrinol Metab. (2008) 93:1129-34. doi: 10.1210/jc.2007-1328

12. Hayashi YK, Matsuda C, Ogawa M, Goto K, Tominaga K, Mitsuhashi $S$, et al. Human PTRF mutations cause secondary deficiency of caveolins resulting in muscular dystrophy with generalized lipodystrophy. J Clin Invest. (2009) 119:2623-33. doi: 10.1172/JCI 38660

13. Shindou H, Hishikawa D, Harayama T, Yuki K, and Shimizu T. Recent progress on acyl CoA: lysophospholipid acyltransferase research. J Lipid Res. (2009) 50:S46-51. doi: 10.1194/jlr.R800035JLR200

14. Subauste AR, Das AK, Li X, Elliot B, Evans C, El Azzouny M, et al. Alterations in lipid signaling underlie lipodystrophy secondary to AGPAT2 mutations. Diabetes. (2012) 61:2922-31. doi: 10.2337/db1 2-0004

15. Cortés VA, Curtis DE, Sukumaran S, Shao X, Parameswara V, Rashid S, et al. Molecular mechanisms of hepatic steatosis and insulin resistance in the AGPAT2 deficient mouse model of congenital generalized lipodystrophy. Cell Metab. (2009) 9:165-76. doi: 10.1016/j.cmet.2009.01.002

16. Triantafyllou GA, Paschou SA, Mantzoros CS. Leptin and hormones: energy homeostasis. Endocrinol Metab Clin North Am. (2016) 45:633-45. doi: 10.1016/j.ecl.2016.04.012

\section{ACKNOWLEDGMENTS}

We thank patients and their relatives for their availability to participate to this study. We also thank Martina Passetto, Massimiliano Benvenuti, and Melania Paoli for their help in managing patients' samples.

17. Chiquette E, Oral EA, Garg A, Araújo-Vilar D, Dhankhar P. Estimating the prevalence of generalized and partial lipodystrophy: findings and challenges. Diabetes Metab Syndr Obes. (2017) 10:375-83. doi: 10.2147/DMSO. S130810

18. De Azevedo Medeiros LB, Cândido Dantas VK, Craveiro Sarmento AS, Agnez-Lima LF, Meireles AL, Xavier Nobre TT, et al. High prevalence of Berardinelli-Seip Congenital Lipodystrophy in Rio Grande do Norte State, Northeast Brazil. Diabetol Metab Syndr. (2017) 9:80. doi: 10.1186/s13098-017-0280-7

19. Magré J, Delépine M, Van Maldergem L, Robert JJ, Maassen JA, Meier $M$, et al. Prevalence of mutations in AGPAT2 among human lipodystrophies. Diabetes. (2003) 52:1573-8. doi: 10.2337/diabetes.52.6. 1573

20. Giannetti M, Piaggi P, Ceccarini G, Mazzeo S, Querci G, Fierabracci P, et al. Hepatic left lobe volume is a sensitive index of metabolic improvement in obese women after gastric banding. Int J Obes. (2012) 36:336-41. doi: 10.1038/ijo.2011.243

21. Agarwal AK, Garg A. Genetic disorders of adipose tissue development, differentiation, and death. Annu Rev Genomics Hum Genet. (2006) 7:175-99. doi: 10.1146/annurev.genom.7.080505.115715

22. Haghighi A, Razzaghy-Azar M, Talea A, Sadeghian M, Ellard S, Haghighi A. Identification of a novel nonsense mutation and a missense substitution in the AGPAT2 gene causing congenital generalized lipodystrophy type 1. Eur J Med Genet. (2012) 55:620-24. doi: 10.1016/j.ejmg.2012. 07.011

23. Ramanathan N, Ahmed M, Raffan E, Stewart CL, O'Rahilly S, Semple RK, et al. Identification and characterisation of a novel pathogenic mutation in the human lipodystrophy gene AGPAT2: C48R: a novel mutation in AGPAT2. JIMD Rep. (2013) 9:73-80. doi: 10.1007/978-3-642-355189_196

24. Akinci B, Onay H, Demir T, Ozen S, Kayserili H, Akinci G, et al. Natural history of congenital generalized lipodystrophy: a nationwide study from Turkey. J Clin Endocrinol Metab. (2016) 101:2759-67. doi: 10.1210/jc.2016-1005

25. Poovazhagi V, Shanthi S, Jahnavi S, Radha V, Mohan V. Berardinelli Seip congenital lipodystrophy presenting with neonatal diabetes mellitus due to a mutation in the AGPAT2 gene. Int J Diabetes Dev C. (2013) 33:66-8. doi: 10.1007/s13410-012-0099-6

26. Jahnavi S, Poovazhagi V, Mohan V, Bodhini D, Raghupathy P, Amutha A, et al. Clinical and molecular characterization of neonatal diabetes and monogenic syndromic diabetes in Asian Indian children. Clin Genet. (2013) 83:439-45. doi: 10.1111/j.1399-0004.2012.01939.x

27. Haque W, Garg A, Agarwal AK. Enzymatic activity of naturally occurring 1-acylglycerol-3-phosphate-O-acyltransferase 2 mutants associated with congenital generalized lipodystrophy. Biochem Biophys Res Commun. (2005) 327:446-53. doi: 10.1016/j.bbrc.2004. 12.024

28. Haghighi A, Kavehmanesh Z, Haghighi A, Salehzadeh F, Santos-Simarro F, Van Maldergem L, et al. Congenital generalized lipodystrophy: identification of novel variants and expansion of clinical spectrum. Clin Genet. (2016) 89:434-41. doi: 10.1111/cge.12623

29. Debray FG, Baguette C, Colinet S, Van Maldergem L, Verellen-Dumouin C. Early infantile cardiomyopathy and liver disease: a multisystemic disorder caused by congenital lipodystrophy. Mol Genet Metab. (2013) 109:227-9. doi: 10.1016/j.ymgme.2013.04.011

30. Agarwal AK, Simha V, Oral EA, Moran SA, Gorden P, O'Rahilly $\mathrm{S}$, et al. Phenotypic and genetic heterogeneity in congenital 
generalized lipodystrophy. J Clin Endocrinol Metab. (2003) 88:4840-7. doi: 10.1210/jc.2003-030855

31. Cortés VA, Smalley SV, Goldenberg D, Lagos CF, Hodgson MI, Santos JL. Divergent metabolic phenotype between two sisters with congenital generalized lipodystrophy due to double AGPAT2 homozygous mutations. a clinical, genetic and in silico study. PLoS ONE. (2014) 9:e87173. doi: 10.1371/journal.pone.0087173

32. Miranda DM, Wajchenberg BL, Calsolari MR, Aguiar MJ, Silva JM, Ribeiro MG, et al. Novel mutations of the BSCL2 and AGPAT2 genes in 10 families with Berardinelli-Seip congenital generalized lipodystrophy syndrome. Clin Endocrinol. (2009) 71:512-7. doi: 10.1111/j.1365-2265.2009. 03532.x

33. Pelosini C, Martinelli S, Bagattini B, Pucci E, Fierabracci P, Scartabelli G, et al. Description of an AGPAT2 pathologic allelic variant in a 54-year-old Caucasian woman with Berardinelli-Seip syndrome. Acta Diabetol. (2011) 48:243-6. doi: 10.1007/s00592-011-0308-7

34. Ben Turkia H, Tebib N, Azzouz H, Abdelmoula MS, Ben Chehida A, Hubert $\mathrm{P}$, et al. Congenital generalized lipodystrophy: a case report with neurological involvement. Arch Pediatr. (2009) 16:27-31. doi: 10.1016/j.arcped.2008.10.005

35. Teboul-Coré S, Rey-Jouvin C, Miquel A, Vatier C, Capeau J, Robert $\mathrm{JJ}$, et al. Bone imaging findings in genetic and acquired lipodystrophic syndromes: an imaging study of 24 cases. Skeletal Radiol. (2016) 45:1495-506. doi: $10.1007 / \mathrm{s} 00256-016-2457-9$

36. Rostami P, Nakhaeimoghadam M, Bijani FM, Sotoudeh A, Rabbani A, Hilbert P, et al. AGPAT2 gene mutation in a child with BerardinelliSeip congenital lipodystrophy syndrome. Ann Endocrinol. (2013) 74:59-61. doi: 10.1016/j.ando.2012.11.008

37. Fu M, Kazlauskaite R, Baracho Mde F, Santos MG, Brandão-Neto J, Villares S, et al. Mutations in Gng3lg and AGPAT2 in Berardinelli-Seip congenital lipodystrophy and Brunzell syndrome: phenotype variability suggests important modifier effects. J Clin Endocrinol Metab. (2004) 89:291622. doi: 10.1210/jc.2003-030485

38. Ponte CMM, Fernandes VO, Gurgel MHC, Vasconcelos ITGF, Karbage LBAS, Liberato CBR, et al. Early commitment of cardiovascular autonomic modulation in Brazilian patients with congenital generalized lipodystrophy. BMC Cardiovasc Disord. (2018) 18:6. doi: 10.1186/s12872-017-0738-4

39. Gomes KB, Fernandes AP, Ferreira AC, Pardini H, Garg A, Magré J, et al. Mutations in the seipin and AGPAT2 genes clustering in consanguineous families with Berardinelli-Seip congenital lipodystrophy from two separate geographical regions of Brazil. J Clin Endocrinol Metab. (2004) 89:357-61. doi: 10.1210/jc.2003-030415

40. Barra CB, Savoldelli RD, Manna TD, Kim CA, Magre J, Porta G, et al. Genetic and metabolic description of five patients with BerardinelliSeip syndrome. Arq Bras Endocrinol Metabol. (2011) 55:54-9. doi: 10.1590/S0004-27302011000100007

41. Oswiecimska J, Dawidziuk M, Gambin T, Ziora K, Marek M, Rzonca S, et al. A Patient with Berardinelli-Seip Syndrome, novel AGPAT2 splicesite mutation and concomitant development of non-diabetic polyneuropathy. J Clin Res Pediatr Endocrinol. (2018) 11:319-26. doi: 10.4274/jcrpe.0227
42. Shetty S, Chapla A, Kapoor N, Thomas N, Paul TV. A novel variant of the AGPAT2 mutation in generalized congenital lipodystrophy, detected by next generation sequencing. Australas Med J. (2016) 9:164-8. doi: 10.21767/AMJ.2016.2640

43. Taleban S, Carew HT, Dichek HL, Deeb SS, Hollenback D, Weigle DS, et al. Energy balance in congenital generalized lipodystrophy type I. Metabolism. (2008) 57:1155-61. doi: 10.1016/j.metabol.2008. 04.008

44. Liu Y, Li D, Ding Y, Kang L, Jin Y, Song J, et al. Further delineation of AGPAT2 and BSCL2 related congenital generalized lipodystrophy in young infants. Eur J Med Genet. (2018) 62:103542. doi: 10.1016/j.ejmg.2018. 09.009

45. Lupsa BC, Sachdev V, Lungu AO, Rosing DR, Gorden P. Cardiomyopathy in congenital and acquired generalized lipodystrophy: a clinical assessment. Medicine. (2010) 89:245-50. doi: 10.1097/MD.0b013e3181e9442f

46. Hussain I, Patni N, Garg A. Lipodystrophies, dyslipidaemias and atherosclerotic cardiovascular disease. Pathology. (2019) 51:202-12. doi: 10.1016/j.pathol.2018.11.004

47. Lima JG, Nobrega LHC, Lima NN, Dos Santos MCF, Silva PHD, Baracho MFP, et al. Causes of death in patients with Berardinelli-Seip congenital generalized lipodystrophy. PLOS ONE. (2018) 8:e0199052. doi: 10.1371/journal.pone.0199052

48. Bhayana S, Siu VM, Joubert GI, Clarson CL, Cao H, Hegele RA. Cardiomyopathy in congenital complete lipodystrophy. Clin Genet. (2002) 61:283-7. doi: 10.1034/j.1399-0004.2002.61 0407.x

49. Van Maldergem L, Magré J, Khallouf TE, Gedde-Dahl T Jr, Delépine $\mathrm{M}$, Trygstad O, et al. Genotype-phenotype relationships in BerardinelliSeip congenital lipodystrophy. J Med Genet. (2002) 39:722-33. doi: 10.1136/jmg.39.10.722

50. Craveiro Sarmento AS, Ferreira LC, Lima JG, de Azevedo Medeiros LB, Barbosa Cunha PT, Agnez-Lima LF, et al. The worldwide mutational landscape of Berardinelli-Seip congenital lipodystrophy. Mutat Res. (2019) 781:30-52. doi: 10.1016/j.mrrev.2019.03.005

Conflict of Interest: The authors declare that the research was conducted in the absence of any commercial or financial relationships that could be construed as a potential conflict of interest.

The reviewer GA declared a past co-authorship with the authors GC and FS to the handling editor.

Copyright (๑ 2020 Ceccarini, Magno, Pelosini, Ferrari, Sessa, Scabia, Maffei, Jéru, Lascols, Vigouroux and Santini. This is an open-access article distributed under the terms of the Creative Commons Attribution License (CC BY). The use, distribution or reproduction in other forums is permitted, provided the original author(s) and the copyright owner(s) are credited and that the original publication in this journal is cited, in accordance with accepted academic practice. No use, distribution or reproduction is permitted which does not comply with these terms. 